\title{
Metallization-induced spontaneous silicide formation at room temperature: The Fe/Si case
}

\author{
J. M. Gallego, J. M. García, J. Alvarez, and R. Miranda \\ Departamento de Física de la Materia Condensada, Universidad Autónoma de Madrid, Cantoblanco, 28049-Madrid, Spain
}

(Received 9 March 1992; revised manuscript received 2 July 1992)

\begin{abstract}
The composition of the interface resulting from the room-temperature deposition of iron on $\operatorname{Si}(100)$ under ultrahigh-vacuum conditions has been monitored by surface-sensitive techniques such as Auger electron spectroscopy, low-energy electron diffraction, and photoemission spectroscopy with synchrotron radiation. The results show unequivocally that the $\mathrm{Fe} / \mathrm{Si}$ interface is not abrupt, but rather an amorphous intermixed region with composition close to $\mathrm{Fe}_{3} \mathrm{Si}$. The formation of this silicidelike layer is related to the metallization of the deposited Fe overlayer. Upon annealing a thick film of Fe, we demonstrate that $\mathrm{Fe}_{3} \mathrm{Si}$ is the first phase to nucleate, in opposition to standard models that point to $\mathrm{FeSi}$ as the first silicide formed.
\end{abstract}

\section{INTRODUCTION}

Recently a great deal of work has been dedicated to the growth and characterization of iron silicides. Most of this attention has centered in $\beta-\mathrm{FeSi}_{2}$, the only iron silicide, and one of the few among the transition-metal silicides, known to be semiconducting, with a band gap, presumably direct, of $\approx 0.9 \mathrm{eV} .{ }^{1,2}$ In an attempt to improve the surface morphology and crystalline quality of $\beta$-FeSi ${ }_{2}$ grown epitaxially on $\mathrm{Si}$, the interest has shifted to characterize the $\mathrm{Fe} / \mathrm{Si}$ interface and the first silicide formed during annealing under ultrahigh-vacuum (UHV) conditions. In spite of the work done, ${ }^{2-12}$ contradictions abound. In particular, the sequence of phase formation is still unclear. In addition to basic issues, there are two practical reasons for which this information must be obtained. First, only with this information can the quantity of silicon consumed in the reaction be determined. The second is to allow prediction of the electrical characteristics of the silicide/silicon contacts. ${ }^{13}$

Early studies ${ }^{3}$ of the $\mathrm{Fe} / \mathrm{Si}$ system using Rutherford backscattering spectrometry (RBS) and x-ray diffraction (XRD) showed that $\mathrm{Fe}_{3} \mathrm{Si}$ and $\mathrm{FeSi}$ formed after annealing a $1340-\AA \mathrm{Fe}$ film on $\mathrm{Si}(100)$ at $\sim 450-525^{\circ} \mathrm{C}$. At $550^{\circ} \mathrm{C}$, an $\mathrm{FeSi}_{2}$ phase grew between the Si substrate and the FeSi phase. The formation sequence was the same on $\mathrm{Si}(111)$, although the silicides formation rates were slightly faster. Transmission electron microscope investigations ${ }^{4}$ found that, for $300-\AA$ Fe films deposited on $\mathrm{Si}$ and annealed in $\mathrm{N}_{2}$ ambient, $\mathrm{FeSi}$ was formed at $400^{\circ} \mathrm{C}$. Small amounts of $\mathrm{Fe}_{3} \mathrm{Si}$ were observed at $450-500^{\circ} \mathrm{C}$. Above $600^{\circ} \mathrm{C}, \beta-\mathrm{FeSi}_{2}$ was the dominant phase, while $\alpha$ $\mathrm{FeSi}_{2}$ was observed only at $800^{\circ} \mathrm{C}$. More recent XRD data $^{5}$ have found that, for $1500-\AA$ Fe films deposited on $\mathrm{Si}(100), \mathrm{Fe}_{3} \mathrm{Si}$ and $\mathrm{FeSi}$ appear after annealings at 600 and $700{ }^{\circ} \mathrm{C}$, respectively. At $750^{\circ} \mathrm{C}$ a mixture of $\mathrm{FeSi}$ and $\beta$ $\mathrm{FeSi}_{2}$ is obtained, while for temperatures between 800 and $900^{\circ} \mathrm{C}$ only $\beta-\mathrm{FeSi}_{2}$ is observed. At higher temperatures $\left(950-1100^{\circ} \mathrm{C}\right)$ the metallic $\alpha-\mathrm{FeSi}_{2}$ is formed.

All experiments mentioned above were performed using conventional vacuum techniques. In UHV, and for much thinner Fe films $(20-30 \AA)$ deposited on $\mathrm{Si}(111)$,
Auger electron spectroscopy (AES) and electron energyloss spectroscopy (EELS) (Refs. 9 and 10) show that FeSi is formed at temperatures ranging from 350 to $500^{\circ} \mathrm{C}$, while $\beta$ - $\mathrm{FeSi}_{2}$ appears between 500 and $650{ }^{\circ} \mathrm{C}$. On $\mathrm{Si}(100), \mathrm{FeSi}$ appears at $300-425^{\circ} \mathrm{C}$, and $\mathrm{FeSi}_{2}$ between 500 and $625^{\circ} \mathrm{C} . .^{11}$

While there is agreement in the fact that the formation temperature of the different phases depends on the vacuum conditions, the sequence of formation remains in dispute. Surprisingly, none of the measurements performed in UHV has detected the formation of $\mathrm{Fe}_{3} \mathrm{Si}$, while for films deposited under conventional vacuum it is normally found at temperatures lower than that where FeSi appears.

As we shall see, the first phase to nucleate during annealings of $\mathrm{Fe} / \mathrm{Si}$ couples is closely related to the actual composition of the as-deposited $\mathrm{Fe} / \mathrm{Si}$ interface. However, before the work at hand, the exact nature of this interface was disputed. On $\mathrm{Si}(111)(7 \times 7)$ the LEED pattern corresponding to an $\mathrm{Fe}(111)$ bcc surface was observed when the thickness of the film became large enough $(\approx 20$ $\mathrm{ML}$ ), which suggests that $\mathrm{Fe}$ forms on this surface an epitaxial layer. ${ }^{12}$ Nevertheless, Auger data indicate a deviation from ideal layer-by-layer growth after the deposition of the second $\mathrm{Fe}$ layer. In spite of this, Urano et al. ${ }^{12}$ claimed that the $\mathrm{Fe} / \mathrm{Si}$ interface was abrupt. On the contrary, based on photoemission data, a thin, intermixed layer of $\beta-\mathrm{FeSi}_{2}$ (Refs. 6 and 7) or FeSi (Ref. 8) has been proposed to exist at the $\mathrm{Fe} / \mathrm{Si}$ interface. At very high coverages, a pure $\mathrm{Fe}$ overlayer has always been found.

In this paper, we report the growth and characterization of $\mathrm{Fe}$ on $\mathrm{Si}(100)$. Our results show that the $\mathrm{Fe} / \mathrm{Si}$ interface at room temperature is far from being atomically abrupt. Rather, a mixed amorphous region forms which composition is close to $\mathrm{Fe}_{3} \mathrm{Si}$, and not $\mathrm{FeSi}_{2}$ or $\mathrm{FeSi}$ as previously reported. Upon annealing a $\mathrm{Fe} / \mathrm{Si}$ couple in $\mathrm{UHV}$, we demonstrate that $\mathrm{Fe}_{3} \mathrm{Si}$ is the first phase to nucleate.

\section{EXPERIMENT}

The experiments have been carried out in an UHV vacuum chamber equipped with surface-sensitive analytical 
techniques such as AES, EELS, and LEED. The base pressure was $2 \times 10^{-10}$ torr. After introduction in the vacuum chamber, and when the pressure was in the $10^{-10}$ range, the sample was annealed resistively for a few seconds to $1200^{\circ} \mathrm{C}$, cooled quickly to $900^{\circ} \mathrm{C}$, and then let slowly cooled to room temperature. This procedure always resulted in a clear and sharp $2 \times 1$ two-domain LEED pattern, while no traces of contamination $(\mathrm{C}, \mathrm{O})$ could be detected with AES. The temperature of the sample was measured with a $\mathrm{Cr}-\mathrm{Al}$ thermocouple, and checked in the high-temperature range with an optical pyrometer.

Iron was evaporated from an Fe wire wrapped around a tungsten wire through which current passed. The pressure during evaporation did not exceed $2 \times 10^{-9}$ torr. After each run of measurements, the sample was cleaned by cycles of $\mathrm{Ar}^{+}$sputtering and annealing until a sharp LEED pattern similar to that of the original surface was recovered and no Fe signal could be detected with AES.

The Auger spectra were taken with a single pass cylindrical mirror analyzer (CMA) equipped with a coaxial electron gun which provided a typical sample current of $\approx 1 \mu \mathrm{A}$. The resolution of the analyzer, measured as the half-width of the elastic peak, was $0.7 \%$. The spectra were taken in derivative mode, modulating the voltage ramp $\left(1 V_{p p}\right)$ and synchronously detecting the collected signal with a lock-in amplifier. When necessary, the spectra were numerically integrated.

The photoemission measurements were carried out at Berliner Elektronenspeicherring-Gesellschaft Für Synchrotronstrahlung m.b.H. (BESSY), where synchrotron radiation from the storage ring was dispersed by an SX700 monochromator and the photoelectrons detected by an hemispherical analyzer.

\section{THE Fe/Si INTERFACE AT ROOM TEMPERATURE}

Figure 1 shows a typical series of Auger spectra taken during $\mathrm{Fe}$ deposition on $\mathrm{Si}(100)$ at room temperature. The spectrum (a), corresponding to the clean Si surface, shows a sharp maximum at $87.3 \mathrm{eV}$, and other less pronounced structures at 41.5, 52.9, 70.5, 81.0, and $103.2 \mathrm{eV}$. All these peaks are due to Si $L V V$ Auger transitions, ${ }^{14}$ although those at 70.5 and $52.9 \mathrm{eV}$ contain contributions from plasma losses of the main peak. ${ }^{15}$ Upon Fe deposition, a new maximum appears at $42.4 \mathrm{eV}$, corresponding to the $M V V$ Auger transition of Fe. ${ }^{16}$

The Fe coverage has been determined by using a previous Auger calibration. ${ }^{11}$ In that work, we reported plots of the intensity of the main $\mathrm{Fe}$ and $\mathrm{Si}$ transitions (measured as the peak to peak height in the derivative spectra) as a function of the evaporation time where a clear break signalled the completion of the first Fe monolayer. However, after this point no more breaks could be distinguished, and the intensity evolution indicated that, above this coverage, the growth mode deviate from a layer-by-layer type. ${ }^{11}$ The present data confirm those previous reports.

No LEED pattern can be seen after deposition of the first $\mathrm{Fe}$ monolayer, suggesting that the atoms in this layer do not sustain a large range order. Up to the coverages measured in these experiments $(\sim 30 \mathrm{ML})$ no LEED pattern appears with further $\mathrm{Fe}$ deposition.

Auger transitions of the $X V V$ type, involving the valence band, are very sensitive to changes in the valence-band density of states (DOS) projected locally on the atom where the initial core hole is produced. ${ }^{17}$ They are, therefore, suitable to detect the onset of reactions that modify the chemical environment of $\mathrm{Si}$ atoms. The kinetic energy of the main $\mathrm{Si}$ peak shifts continuously from 87.3 to $86.5 \mathrm{eV}$ for $\mathrm{Fe}$ coverages up to $1.1 \mathrm{ML}$. In the range from 1.1 to $5.0 \mathrm{ML}$, the energy position remains constant at $86.5 \mathrm{eV}$. From 5.0 ML on, the energy diminishes again until, at $\sim 7 \mathrm{ML}$, it saturates at 82.7 $\mathrm{eV}$ (see the inset in Fig. 1). The kinetic energy of an Auger transition can be written as $E_{K}(L V V)=E_{L}$ $-2 E_{V}-V_{\text {eff }}$, where $E_{L}$ is the energy of the core level, $E_{V}$ the centroid of the valence-band DOS, and $V_{\text {eff }}$ includes correlation effects (small for $\mathrm{Si}$ and $\mathrm{Fe}$ ). During $\mathrm{Fe}-\mathrm{Si}$ chemical bonding and silicide formation, both core level $\left(E_{L}\right)$ and valence band $\left(E_{V}\right)$ are modified (see below). Accordingly, we interpret the kinetic-energy shift as indicating the formation of some chemical compound between $\mathrm{Si}$ and $\mathrm{Fe}$. The constant value between 1.1 and $5 \mathrm{ML}$ indicates a stable chemical environment for the detected $\mathrm{Si}$ atoms, i.e., a compound of well-defined stoichiometry is formed at room temperature during $\mathrm{Fe}$ deposition from $\sim 1$ to $\sim 5$ ML.

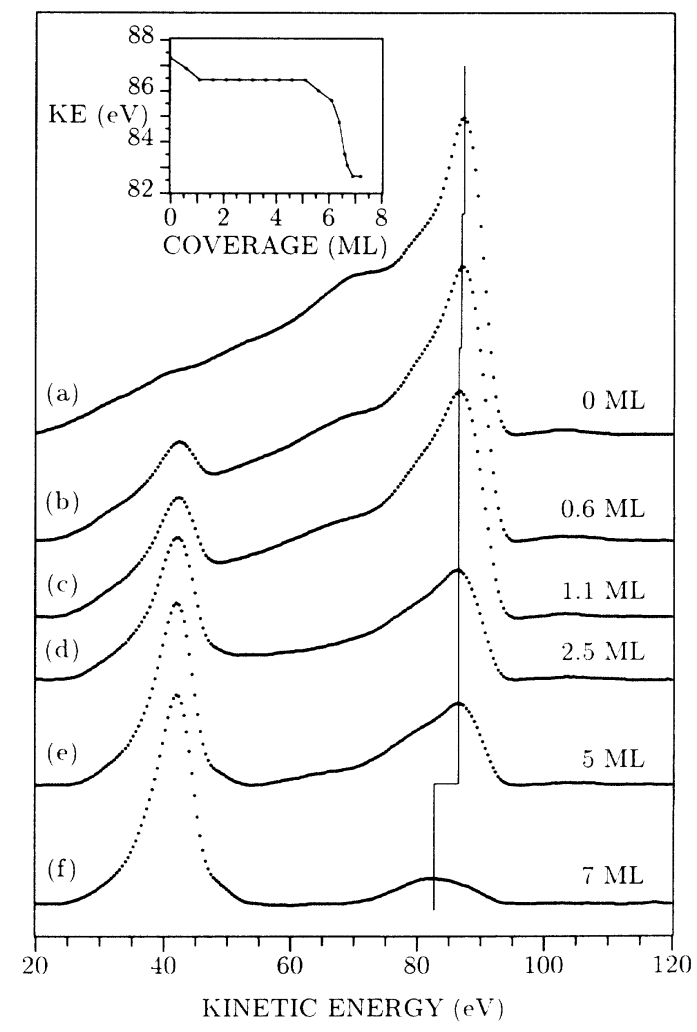

FIG. 1. Evolution of the low-energy Auger spectra in integral form (Fe $M_{23} V V$ and $\mathrm{Si} L_{23} V V$ while depositing $\mathrm{Fe}$ on $\mathrm{Si}(100)$ at room temperature. The inset shows the shift in the kinetic energy of the main Si peak at a function of Fe coverage. 
In Fig. 2 the evolution of the Si peak intensity is depicted logarithmically as a function of $\mathrm{Fe}$ coverage. The same three regions $(0-1,1-5$, and from $5 \mathrm{ML}$ on) can clearly be distinguished. The data confirm that the growth mode is not layer-by-layer (in this case only one linear region is expected $\left.{ }^{11}\right)$. The experimental points for coverages between 0 and $1 \mathrm{ML}$ can be fitted with a straight line; the attentuation coefficient obtained from its slope is $\alpha=0.60$. On the other hand, a linear fit to the points between 1 and $5 \mathrm{ML}$ gives an attenuation coefficient $\alpha=0.78$. From $5 \mathrm{ML}$ on, a value of $\alpha=0.55$, close to the initial one, results. From the measured values of the attenuation coefficients the average composition of the reacted layer can be obtained.

If we assume that the transmission of electrons of 87.3-eV kinetic energy through a complete and uniform Fe layer proceeds with a coefficient of 0.6 , the larger value of $\alpha$ obtained between 1 and $5 \mathrm{ML}$ would correspond to the transmission of electrons through a film whose relative $\mathrm{Fe}$ composition is $75 \%$, the $25 \%$ left being $\mathrm{Si}$ atoms, i.e., the stoichiometry of this intermixed layer is $\mathrm{Fe}_{3} \mathrm{Si}$.

We can summarize the growth mode of $\mathrm{Fe}$ on $\mathrm{Si}(100)$ at room temperature as follows: the first $\mathrm{Fe}$ monolayer covers the Si surface almost uniformly, although in a disordered way, as evidenced by the absence of any LEED pattern. Further Fe evaporation produces a spontaneous reaction between $\mathrm{Fe}$ and $\mathrm{Si}$ at room temperature, to give an amorphous region (since no LEED pattern is seen) whose composition is close to $\mathrm{Fe}_{3} \mathrm{Si}$. Above a coverage of $5 \mathrm{ML}$ the reaction slows down noticeably, and the $\mathrm{Si}$ dissolution in the overlayer diminishes, this latter being more and more Fe rich, until an almost uniform (although also disordered) and metallic Fe layer is formed. It is, however, remarkable that some $\mathrm{Si}$ signal is detected even after the deposition of $20 \mathrm{ML}$ of $\mathrm{Fe}$, indicating that still after this coverage there are some $\mathrm{Si}$ atoms dissolved in the Fe matrix.

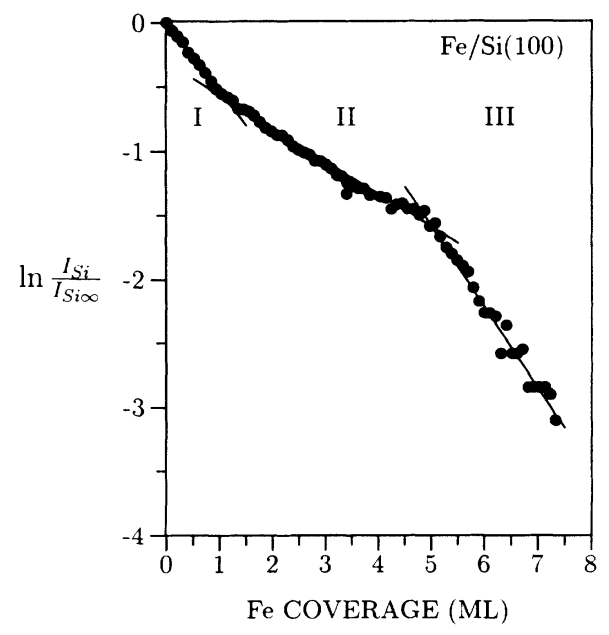

FIG. 2. Intensity (referred to the initial one) of the Si lowenergy Auger transition while depositing $\mathrm{Fe}$ on $\mathrm{Si}(100)$. Regions I-III are discussed in the text. Region II reflects the formation at room temperature of a reacted silicidelike overlayer.
This mode of growth can explain the shifts in energy of the main Si peak shown in the right panel of Fig. 1. Between 0 and $1 \mathrm{ML}$, the energy position of the Si peak shifts in an almost continuous way to lower kinetic energy due to the growing number of $\mathrm{Si}$ atoms bonded to $\mathrm{Fe}$. Between $\sim 1$ and $\sim 5 \mathrm{ML}$, the energy position of the main peak remains constant, most of the signal being due to the $\mathrm{Si}$ atoms in the silicidelike layer. From this moment on, the detected signal is probably due to the $\mathrm{Si}$ atoms dissolved in the $\mathrm{Fe}$ matrix. The attenuation coefficient is again close to the original one, supporting this conclusion.

The proposed formation of a $\mathrm{Fe}_{3} \mathrm{Si}$ compound can be confirmed by measuring the DOS at the valence band with photoemission. Figure 3 shows the evolution of the valence-band spectra, taken with a photon energy $h v=130 \mathrm{eV}$, during the growth of $\mathrm{Fe}$ on $\mathrm{Si}(100)$. The spectrum (a) corresponds to the clean and $2 \times 1$ reconstructed $\mathrm{Si}(100)$ surface. The distance from the valenceband edge to the Fermi level, $E_{F}-E_{V}$, is $0.37 \mathrm{eV}$, in agreement with previous results. ${ }^{18}$ The peak at $\sim 1 \mathrm{eV}$ below $E_{F}$, labeled $S_{1}$, is due to the emission from the danglingbond surface states. ${ }^{18}$ Peak $D$, at $\sim 7.5 \mathrm{eV}$, has been assigned to transitions from a high density of bulk states along $X-W$ without conservation of $k_{1} \cdot{ }^{19}$ The maximum $B_{1}($ at $\sim 2.8 \mathrm{eV})$ and the feature $B_{2}($ at $\sim 4.6 \mathrm{eV})$ are due to direct transitions from the bulk states. ${ }^{19}$

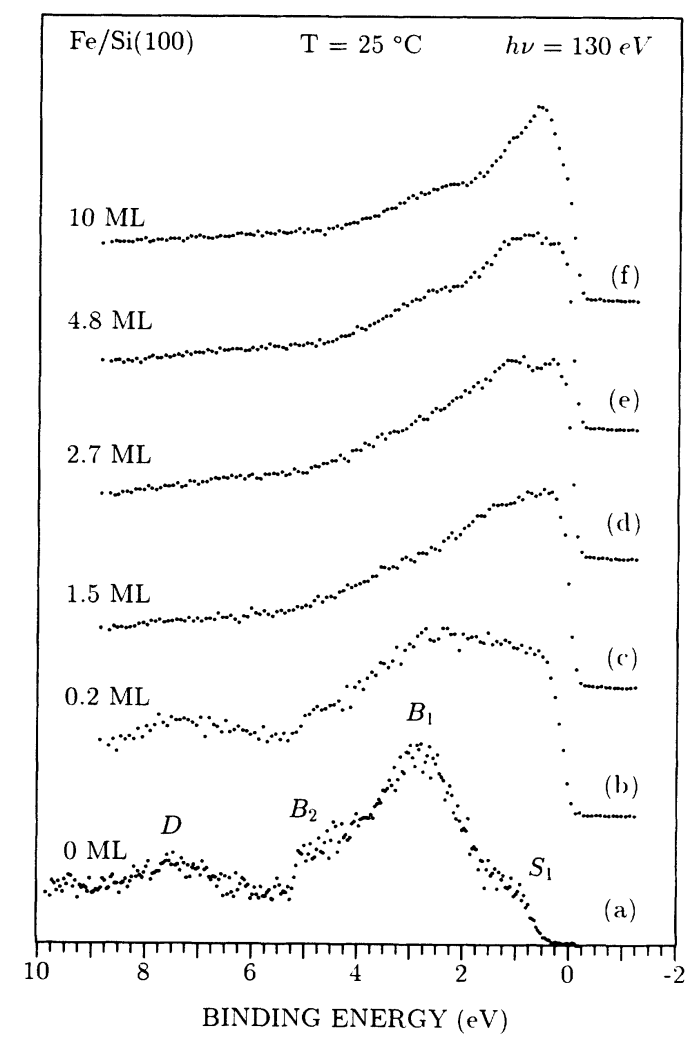

FIG. 3. Valence-band spectra taken during the deposition of $\mathrm{Fe}$ on $\mathrm{Si}(100)$ at room temperature. The photon energy was 130 $\mathrm{eV}$, and the binding-energy scale is referred to the Fermi level. The spectra have been normalized to the same height. 
After depositing 0.2 ML of Fe, the surface-state emission $S_{1}$ disappears and the valence-band edge moves closer to $E_{F}$, while a broad emission appears from 0.8 to $1.8 \mathrm{eV}$. For $1.5 \mathrm{ML}$ of $\mathrm{Fe}$, none of the features associated with bulk Si remain [the mean free path for electrons of $125-\mathrm{eV}$ kinetic energy is $\approx 2 \mathrm{ML}$ (Ref. 20)] while those of bulk $\mathrm{Fe}$ are not yet detected. There is a large peak at $\sim 0.35 \mathrm{eV}$, with a weak structure at $\sim 1.15 \mathrm{eV}$. At this coverage the surface can certainly be considered as metallic, due to a noticeable density of states at the Fermi level. At $2.7 \mathrm{ML}$, the spectrum is dominated by two peaks at 1.15 and $0.35 \mathrm{eV}$, respectively. After $4.8 \mathrm{ML}$, both peaks are less resolved due to the appearance of a new structure at $0.65 \mathrm{eV}$, assigned to $\mathrm{Fe} 3 d$ states in bcc $\mathrm{Fe}$, which dominates the spectrum at $10 \mathrm{ML}$. The line shape, width of the valence band, and peak positions of this latter spectrum, with a leading peak at $0.65 \mathrm{eV}$ and a broader one at $2.6 \mathrm{eV}$ are quite similar to those reported for clean $\mathrm{Fe}^{21,22}$ In conclusion, the valence-band spectra taken after depositing 1.5, 2.7, and 4.8 ML of Fe show features that do not appear in the spectrum of clean $\mathrm{Si}$ nor in that of pure Fe. They reflect the formation of a silicidelike layer, in accordance with the above-mentioned interpretation.

According to a detailed photoemission study of iron silicides, ${ }^{23}$ the compound formed is not $\mathrm{FeSi}$, nor $\beta-\mathrm{FeSi}_{2}$. In $\mathrm{Fe}_{3} \mathrm{Si}$ there are two inequivalent $\mathrm{Fe}$ atoms, one of them (with eight $\mathrm{Fe}$ atoms as nearest neighbors) displays a magnetic moment of $2.3 \mu_{B}$, while the other (with four $\mathrm{Si}$ and four $\mathrm{Fe}$ atoms as nearest neighbors) has a smaller magnetic moment of $1.2 \mu_{B} \cdot{ }^{24}$ Recent calculations for $\mathrm{Fe}_{3} \mathrm{Si}$ (Ref. 25) have revealed that the DOS is clearly different for both $\mathrm{Fe}$ sites. In the vicinity of $E_{F}$ this would lead to a two-peak structure with the same energy position $(0.3-1.15 \mathrm{eV})$ than the one observed in the experimental valence-band spectrum. Accordingly, we identify the silicide formed at the interface during roomtemperature deposition with $\mathrm{Fe}_{3} \mathrm{Si}$.

The evolution of the Si $2 p$ core level with $\mathrm{Fe}$ deposition (Fig. 4) further confirms the formation of a reacted interface. At $1.5 \mathrm{ML}$ of $\mathrm{Fe}$ the Si $2 p$ core-level shifts $\approx 0.1 \mathrm{eV}$ to lower binding energy. At $2.7 \mathrm{ML}$ the shift of the main peak has increased to $\approx 0.25 \mathrm{eV}$, while the line shape clearly indicates the presence of a reacted component at lower binding energy. This component dominates the spectrum at $4.8 \mathrm{ML}$, and is shifted $\approx 0.5 \mathrm{eV}$ to lower binding energy with respect to the bulk Si peak. The core-level shifts are due to charge transfer from $\mathrm{Fe}$ to $\mathrm{Si}$ during silicide formation. The onset of the reaction is detected at 1.5 ML, and, thus, it is found to coincide with the metallization of the overlayer as determined from the valence-band spectra. For 10-ML-thick films of Fe no signal from the $\mathrm{Si} 2 p$ core level could be detected with $h v=130 \mathrm{eV}$.

The direct formation of a mixed amorphous interface has been predicted for metal/silicon interfaces produced by evaporation of the metal onto clean, cold $\mathrm{Si}$ substrates. ${ }^{26}$ However, some results ${ }^{27}$ indicate that a critical deposited thickness is necessary for the intermixing reaction to proceed. This critical thickness is the one required for the complete metallization of the overlayer. In

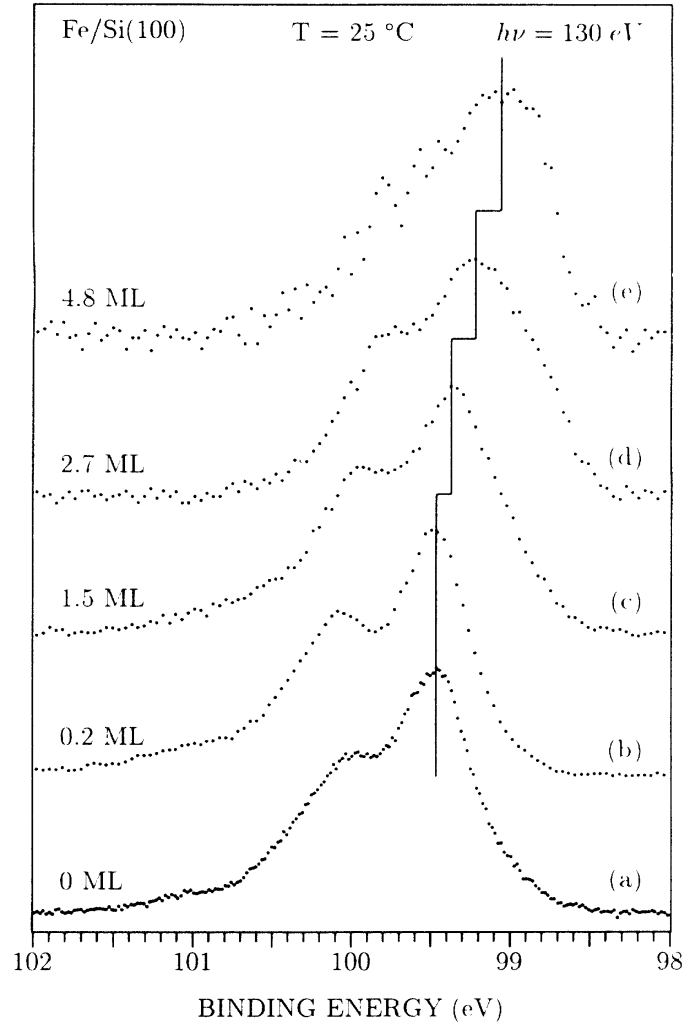

FIG. 4. Si $2 p$ core-level spectra taken with $h v=130 \mathrm{eV}$ during deposition of $\mathrm{Fe}$ on $\mathrm{Si}(100)$. The spectra have been normalized to the same height.

a metallic overlayer the delocalized conduction electrons screen the $\mathrm{Si}-\mathrm{Si}$ bonds, producing their weakening and thus allowing the intermixing reaction to occur. The results of the work at hand are in accordance with this idea. In the $\mathrm{Fe} / \mathrm{Si}$ case, the critical $\mathrm{Fe}$ coverage determined by AES seems to be $\sim 1 \mathrm{ML}$ of $\mathrm{Fe}$, which coincides with the point where the surface can be taken as metallic, as evidenced by the photoemission data.

Similar results have recently been published for the $\mathrm{Au} / \mathrm{Si}(111)$ interface. ${ }^{28}$ In this case the critical Au thickness for chemical interaction is $\approx 2 \AA$, and is also explained in terms of the evolving electronic structure of Au with increasing Au coverage.

\section{THE PHASE SEQUENCE OF IRON SILICIDES FORMATION}

The fact that $\mathrm{Fe}_{3} \mathrm{Si}$ forms right at the $\mathrm{Fe} / \mathrm{Si}$ interface during room-temperature deposition of $\mathrm{Fe}$ may have profound influence in the sequence of formation of iron silicides during solid phase epitaxy (SPE). The sequence of formation is important to determine the amount of $\mathrm{Si}$ consumed in the reaction and the surface morphology of any given final product (i.e., $\beta$-FeSi ${ }_{2}$ ).

The composition of the first silicide formed during annealing of a $\mathrm{Fe} / \mathrm{Si}$ couple can be determined by AES. The evolution of the high-energy $\mathrm{Fe} L V V$ Auger spectra has been monitored during the annealing of a 30-ML Fe 


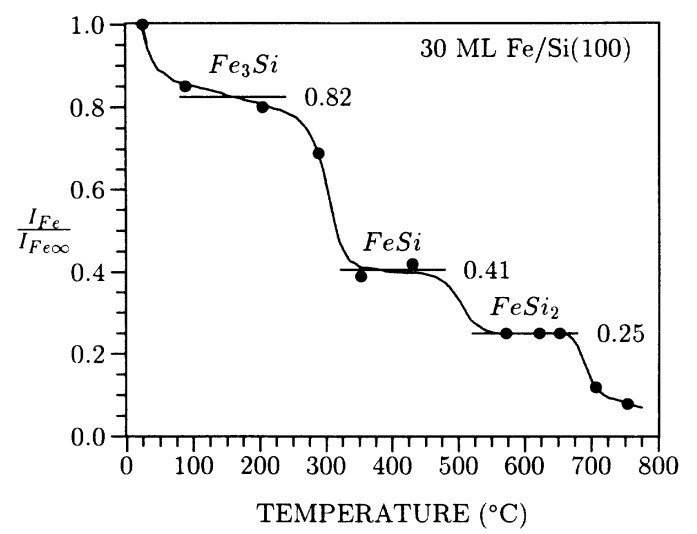

FIG. 5. Intensity evolution of the high-energy Fe Auger transition during annealing a 30-ML Fe film deposited on $\mathrm{Si}(100)$.

film deposited on $\mathrm{Si}(100)$. These spectra have been numerically integrated and the intensity of the highest energy peak (measured as the area between 660 and $740 \mathrm{eV}$ ) is depicted in Fig. 5 versus annealing temperature (the areas have been normalized to that of the Fe peak before annealing). There are plateaus on this plot where the intensity remains approximately constant. The first one ranges from 75 to $175^{\circ} \mathrm{C}$, the second one from 350 to $450^{\circ} \mathrm{C}$, and a last one from 550 to $650^{\circ} \mathrm{C}$.

For a homogeneous film thicker than the corresponding electron mean free path, the intensities of the highenergy Auger peaks should be proportional to the number density of $\mathrm{Fe}$ in the film. This density is 8.46, 6.63, 4.42 , and $2.66 \times 10^{22}$ atoms $/ \mathrm{cm}^{3}$ for $\mathrm{Fe}, \mathrm{Fe}_{3} \mathrm{Si}, \mathrm{FeSi}$, and $\mathrm{FeSi}_{2}$, respectively, which are in a relation 1:0.78:0.52:0.31. The normalized intensities of the highenergy Fe peak measured in the different plateaus are 1, $0.82,0.41$, and 0.25 , respectively. The agreement with the predicted values is excellent, assuring that the phases formed at $75-175^{\circ} \mathrm{C}, 350-450^{\circ} \mathrm{C}$, and $550-650^{\circ} \mathrm{C}$, are, respectively, $\mathrm{Fe}_{3} \mathrm{Si}, \mathrm{FeSi}$, and $\mathrm{FeSi}_{2}$. This result agrees with that of Ref. 9, the only difference being the formation of $\mathrm{Fe}_{3} \mathrm{Si}$ at $100^{\circ} \mathrm{C}$, which is absent in those results and, to our knowledge, in any other performed in UHV conditions. In this connection, we remark that for low coverages (less than $10 \mathrm{ML}$ ) only the last two plateaus are seen. ${ }^{11}$ This can be rationalized by realizing that, in these cases, the room-temperature interface composition is already close to $\mathrm{Fe}_{3} \mathrm{Si}$ and, therefore, no abrupt changes in the $\mathrm{Fe}$ intensity are expected to occur at $100-200^{\circ} \mathrm{C}$. For thicker films, although the composition of the layers near the $\mathrm{Fe} / \mathrm{Si}$ interface is $\mathrm{Fe}_{3} \mathrm{Si}$, most of the deposited thickness is almost pure $\mathrm{Fe}$, which then reacts with $\mathrm{Si}$ at $100-200^{\circ} \mathrm{C}$ to produce a thicker and more detectable $\mathrm{Fe}_{3} \mathrm{Si}$ film.

Several phenomenological rules based in the equilibrium phase diagrams ${ }^{26,29}$ and in the heats of formation ${ }^{30}$ have been formulated to explain the phase formation sequence in a metal/silicon interface. All of them predict $\mathrm{FeSi}$ as the first phase formed in the $\mathrm{Fe} / \mathrm{Si}$ system. We have found conclusive experimental evidence that this is not the case, with $\mathrm{Fe}_{3} \mathrm{Si}$ being actually the first formed phase. We propose that $\mathrm{Fe}_{3} \mathrm{Si}$ is the first phase formed because: (i) it is already present at the room temperature $\mathrm{Fe} / \mathrm{Si}$ interface, i.e., no nucleation barrier exists; and (ii) its crystallographic structure $\left[\mathrm{Fe}_{3} \mathrm{Si}\right.$ is cubic, with a lattice parameter of $5.656 \AA, 16$ atoms per unit cell, and a $\mathrm{Fe}-\mathrm{Fe}$ nearest-neighbor distance of $2.83 \AA$ (Ref. 31)] is very similar to that of pure $\mathrm{Fe}$ (bcc, a lattice parameter of $2.87 \AA$ ).

In summary, the $\mathrm{Fe} / \mathrm{Si}(100)$ interface is reactive at room temperature. Upon deposition of $\mathrm{Fe}$ above $1 \mathrm{ML}$ a spontaneous reaction occurs which results in formation of an amorphous silicide layer with a composition close to $\mathrm{Fe}_{3} \mathrm{Si}$. Above $5 \mathrm{ML}$ the reaction slows down (at room temperature) and a film of metallic polycrystalline $\mathrm{Fe}$ film, with some Si dissolved, develops. During isochronal annealing of the $\mathrm{Fe}$ film, $\mathrm{Fe}_{3} \mathrm{Si}$ forms first, followed by FeSi and $\mathrm{FeSi}_{2}$, each on a well-defined (and coveragedependent) temperature range.

\section{ACKNOWLEDGMENTS}

We are deeply indebted to Professor G. Kaindl, Dr. C. Laubschat, and Dr. S. Molodtsov for their invaluable help during measurements at BESSY. Financial support by the ESPRIT BRA 3026 and the CICYT is gratefully acknowledged.
${ }^{1}$ M. C. Bost and J. E. Mahan, J. Appl. Phys. 58, 2696 (1985).

${ }^{2}$ C. A. Dimitriadis, J. H. Werner, S. Logothetidis, M. Stutzmann, J. Weber, and R. Nesper, J. Appl. Phys. 68, 1726 (1990).

${ }^{3}$ S. S. Lau, J. S. Y. Feng, J. O. Olowolafe, and M. A. Nicolet, Thin Solid Films 25, 415 (1975).

${ }^{4}$ H. C. Cheng, T. R. Yew, and L. J. Chen, J. Appl. Phys. 57, 12 (1985).

${ }^{5}$ C. A. Dimitriadis and J. H. Werner, J. Appl. Phys. 68, 93 (1990).

${ }^{6}$ B. Li, M. Ji, J. Wu, and C. Hsu, J. Appl. Phys. 68, 1099 (1990).

${ }^{7}$ M. de Crescenzi, G. Gaggiotti, N. Motta, F. Patella, A. Balzarotti, and J. Derrien, Phys. Rev. B 42, 5871 (1990).

${ }^{8}$ Y. Ufuktepe and M. Onellion, Solid State Commun. 76, 191 (1990).
${ }^{9}$ Q. G. Zhu, H. Iwasaki, E. D. Williams, and R. L. Park, J. Appl. Phys. 60, 2629 (1986).

${ }^{10}$ A. Rizzi, H. Moritz, and H. Lüth, J. Vac. Sci. Technol. A 9, 912 (1991).

11J. M. Gallego and R. Miranda, J. Appl. Phys. 69, 1377 (1991).

${ }^{12}$ T. Kanaji, T. Urano, A. Hiraki, and M. Iwami, in Proceedings of the 8th International Vacuum Congress, 1980, Cannes, France, edited by F. Abélés and M. Croset (Société Française du Vide, Paris, 1980), Vol. 1, p. 117.

${ }^{13}$ C. R. M. Grovenor, Microelectronic Materials (Hilger, Bristol, 1989).

${ }^{14}$ J. T. Grant and T. W. Haas, Surf. Sci. 23, 347 (1970).

${ }^{15}$ B. A. Joyce and J. H. Neave, Surf. Sci. 27, 499 (1971).

${ }^{16}$ G. W. Simmons and D. J. Dwyer, Surf. Sci. 48, 373 (1975).

${ }^{17}$ M. C. Muñoz, V. Martínez, J. A. Tagle, and J. L. Sacedón, J. 
Phys. C 13, 4247 (1980).

${ }^{18}$ F. J. Himpsel and D. E. Eastman, J. Vac. Sci. Technol. 16, 1297 (1979).

${ }^{19}$ P. Koke, A. Goldmann, W. Mönch, G. Wolfgarten, and J. Pollmann, Surf. Sci. 152/153, 1001 (1985).

${ }^{20}$ M. P. Seah and W. A. Dench, Surf. Interf. Anal. 1, 2 (1979).

${ }^{21}$ M. Pessa, P. Heimann and H. Neddermeyer, Phys. Rev. B 14, 3488 (1976).

${ }^{22}$ A. M. Turner and J. L. Erskine, Phys. Rev. B 30, 6675 (1984).

${ }^{23}$ J. Alvarez, J. J. Hinarejos, E. G. Michel, G. R. Castro, and R. Miranda, Phys. Rev. B 45, 14042 (1992).

${ }^{24}$ W. A. Hines, A. H. Menotti, J. I. Budnick, T. J. Burch, T. Li- trenta, V. Niculescu, and K. Raj, Phys. Rev. B 13, 4060 (1976).

${ }^{25}$ J. Kudrnovsky, N. E. Christensen, and O. K. Andersen, Phys. Rev. B 43, 5924 (1991).

${ }^{26}$ R. M. Walser and R. W. Bené, Appl. Phys. Lett. 28, 624 (1976).

${ }^{27}$ A. Hiraki, Surf. Sci. Rep. 3, 357 (1984).

${ }^{28}$ S. L. Molodtsov, C. Laubschat, G. Kaindl, A. M. Shikin, and V. K. Adamchuk, Phys. Rev. B 44, 8850 (1991).

${ }^{29}$ M. Ronay, Appl. Phys. Lett. 42, 577 (1983).

${ }^{30}$ R. Pretorius, Vacuum 41, 1038 (1990).

${ }^{31}$ B. Egert and G. Panzner, Phys. Rev. B 29, 2091 (1984). 